\title{
Epifanijne doświadczenia krajobrazu w przedwojennej poezji jidyszowej Awroma Suckewera
}

\section{Epiphanic Experience of Landscape in Pre-War Yiddish Poetry of Avrom Sutzkever}

\begin{abstract}
This article analyses the relationship between the subject and the landscape in Avrom Sutzkever's early poetry (primarily focusing on compositions published in the volumes Lider [Poems], from 1937, and Valdiks [Forested], from 1940). The author explores the matter of epiphanic experience of landscape - wherein the stake is the search for metaphysical sense within nature - that is a dominant feature of Sutzkever's pre-war poetry. The way these epiphanies are depicted reveals the romantic-modernist provenance of the early poetic compositions of this Yiddish writer.
\end{abstract}

Keywords: landscape, epiphany, Yiddish literature, Avrom Sutzkever

Streszczenie: Przedmiotem zawartej w artykule analizy jest relacja podmiotu i krajobrazu we wczesnej poezji Awroma Suckewera (przede wszystkim w utworach opublikowanych w tomach Lider [Wiersze] z 1937 roku i Waldiks [Leśne] z 1940 roku). Autorka skupia się na problemie epifanicznego doświadczania krajobrazu, którego stawką jest poszukiwanie metafizycznego sensu w naturze, jako dominującym wyznaczniku przedwojennej twórczości Suckewera. Sposób przedstawiania epifanii ukazuje romantyczno-modernistyczną proweniencję wczesnych utworów poetyckich jidyszowego pisarza.

Słowa kluczowe: krajobraz, epifania, literatura jidysz, Awrom Suckewer

Poezja Awroma Suckewera ${ }^{1}$ stanowi całościowy projekt literacki, który opiera się na cyrkulacji kluczowych motywów i tematów: poznania i ludzkich możliwości poznawczych, indywidualnego i jednostkowego doświadczenia podmiotu

${ }^{1}$ Awrom Suckewer urodził się w 1913 roku w Smorgoniach, zmarł w 2010 roku w Tel Awiwie. Biografia Suckewera (ale również jego twórczość) koncentruje się wokół trzech miejsc: Syberii, Wilna i Tel Awiwu. Po wybuchu I wojny światowej rodzina pisarza uciekła na Syberię, 
(zgodnie z formułą pisania o sobie dla siebie), które w poezji wojennej zostanie skonfrontowane $\mathrm{z}$ losem narodu i podmiotem zbiorowym, a także krajobrazu oraz natury i relacji, jaką nawiązuje z nimi podmiot, czy wreszcie pytania o samą poezję, proces twórczy i powinności poety (Awrom Nowersztern podkreśla nawet, że trudno wskazać utwór, w którym Suckewer nie podejmowałby problemu metapoetyckiego ${ }^{2}$ ). Ze względu na charakterystyczne dla poezji jidyszowego autora powroty stałych tematów Mortche Litwin określił jego twórczość jako „permanentne, nieustanne i zaskakujące odnawianie”, odbywające się zgodnie $\mathrm{z}$ ruchem spirali w różnych czasoprzestrzeniach, poprzez które autor próbuje dosięgnąć czegoś wyższego i dalszego, odkryć nowe i nieznane wymiary doświadczenia ${ }^{3}$.

Poezja Suckewera, szczególnie ta tworzona w okresie przedwojennym, wydaje się bliższa literaturze polskiej (zwłaszcza romantycznej i modernistycznej) $)^{4}$ niż literaturze powstającej w najbliższym otoczeniu kulturowym żydowskiego poety - jidyszowej twórczości grupy literackiej Jung Wilne, mocno osadzonej

gdzie Suckewer spędził dzieciństwo. Od lat trzydziestych mieszkał w Wilnie, gdzie przyłączył się do żydowskiej grupy artystycznej Jung Wilne, w 1937 roku opublikował tu swój debiutancki zbiór poezji pt. Lider. W czasie II wojny światowej przebywał w wileńskim getcie, zaangażował się w działalność żydowskiej partyzantki. We wrześniu 1947 roku Suckewer wraz ze swoją rodziną przybył do Izraela, do końca życia mieszkał w Tel Awiwie. Więcej na temat biografii Suckewera zob. J. Cammy, Abraham Sutzkever (Avrom Sutskever) [w:] Writers in Yiddish, red. J. Sherman, Detroit 2007, s. 303-313; J. Birnbojm, Awrom Suckewer [w:] Der leksikon fun najer jidiszer literatur, t. 6, Nowy Jork 1965, s. 355-367; R. Wisse, Sutzkever, Avrom, YIVO Encyclopedia of Jews in Eastern Europe, 2017, http://www.yivoencyclopedia.org/article.aspx/Sutzkever_Avrom, dostęp: 6.08.2018.

${ }^{2}$ Zob. A. Nowersztern, Der narcis un der regn [w:] Jiches fun lid. Lekowed Awrom Suckewer, red. D. Sadan, Tel Awiw 1983, s. 188.

${ }^{3}$ Zob. M. Litwin, Der driter period in Awrom Suckewers poezje [w:] Jiches fun lid..., dz. cyt., s. 123.

${ }^{4}$ Awrom Suckewer jest jednym z nielicznych pisarzy jidyszowych, który w swojej twórczości problematyzuje kwestię kulturowych i literackich relacji polsko-żydowskich. Dostrzega ich dynamiczną interakcję, a także naturalne pokrewieństwo, którego podstawą jest wspólna historia oraz ten sam krajobraz. W jego poezji można doszukać się zbieżności zarówno z polskim romantyzmem (reprezentowanym przede wszystkim przez Adama Mickiewicza, Cypriana Kamila Norwida, Juliusza Słowackiego), poezją Bolesława Leśmiana, jak i z twórczością grup literackich międzywojnia (na przykład Żagarów czy Drugiej Awangardy). Znamienny w tym kontekście jest napisany tuż po wojnie poemat $\mathrm{Cu}$ Pojln, który Chone Shmeruk interpretował nie tylko jako „pożegnanie oraz wielostronny bolesny żydowski rozrachunek z Polską”, ale przede wszystkim jako rozliczenie fantazmatu polsko-żydowskiego braterstwa. Zob. Ch. Shmeruk, Awrom Suckewer i polska poezja. Juliusz Stowacki w poemacie „Cu Pojln”, tłum. M. Adamczyk-Garbowska [w:] Polskie tematy i konteksty literatury żydowskiej, red. E. Prokop-Janiec, M. Tuszewicki, Kraków 2014, s. 279-290 [Ch. Shmeruk, Awrom Suckewer un pojlisze poezje: Juliusz Slowacki un der poemat "Cu Pojln” [w:] Jiches fun lid..., dz. cyt., s. 280-291]. Kwestia interferencji między poezją Suckewera a polską literaturą wymaga dalszych pogłębionych badań. Zbieżności te traktuję w tym artykule - ze względu na poruszaną w nim inną problematykę - kontekstowo i jedynie je sygnalizuję. 
w kontekście społecznym i politycznym ${ }^{5}$. Przedwojenna twórczość Suckewera stanowi bowiem zapis poszukiwania „więzi mikrokosmosu wewnętrznych przeżyć podmiotu z makrokosmosem wszechświata"; przepełniają ją obrazy przyrody, w której podmiot dostrzega źródło swoich poetyckich inspiracji oraz duchowego ukojenia. Nie brakuje w niej jednak symptomatycznych dla tamtego pokolenia (zarówno Jung Wilne, jak i Żagarów czy Drugiej Awangardy) projekcji katastroficznych związanych z kryzysem współczesnego świata i przeczuciem zbliżającego się końca. W artykule tym proponuję namysł nad dominującym w przedwojennych utworach Suckewera ${ }^{7}$ sprzężeniem trzech powracających tematów: krajobrazu, poezji i doświadczenia, które - jak twierdzę - dokonuje się w epifanicznym przeżywaniu świata oraz poszukiwaniach metafizycznego sensu w naturze.

\section{Doświadczenie bezpośrednie natury}

W debiutanckim tomie Suckewera zatytułowanym Lider Heather Valencia wyróżnia trzy główne konceptualizacje relacji podmiotu do krajobrazu i ogólniej - natury: 1) harmonijne współistnienie poetyckiego ,ja” i przestrzeni natury jako odrębnych od siebie całości, które wywołuje w podmiocie twórczy impuls; 2) dążenie do pełnego połączenia z siłami przyrody przy jednoczesnej walce o zachowanie własnej podmiotowości; 3) koncept poety-twórcy jako centrum uniwersum i mistrza, którego siły poetyckie przewyższają naturę ${ }^{8}$. W twórczości Suckewera krajobraz jest w istocie związany z refleksją metapoetycką, stając się niekiedy metaforą samego procesu twórczego. Wydaje się jednak, że nie stanowi on - jak sugeruje Valencia - jedynie zbioru symboli, które Suckewer nadaje poszczególnym elementom krajobrazowym, ani też nie staje się tylko estetyczną scenerią jego egzystencjalnych i metapoetyckich poszukiwań. Wręcz przeciwnie - postrzeganie krajobrazu oraz odkrywanie piękna natury jest źródłem doświadczenia i estetycznej wrażliwości. Przekonuje o tym

${ }^{5}$ Choć poezja Suckewera, proponująca inną wizję świata skoncentrowaną na wewnętrznym przeżywaniu, nie wpisywała się w ogólne postulaty Jung Wilne, to jednak zajmowała w niej istotne miejsce. Zob. J. Lisek, Jung Wilne - żydowska grupa artystyczna, Wrocław 2005, s. 126-129. Por. J.D. Cammy, „Ceworfene Bleter”: Jung Wilne i kultura jidysz w międzywojennym Wilnie [w:] Poezja i poeci w Wilnie lat 1920-1940. Studia, red. T. Bujnicki, K. Biedrzycki, Kraków 2003, s. 257-286.

${ }^{6}$ Zob. J. Lisek, dz. cyt., s. 128.

Będę odwoływać się do utworów zawartych w debiutanckim tomie Lider [Wiersze], zob. A. Suckewer, Lider, Warszawa 1937 (cytowany fragment utworu oznaczam literą L i podaję numer strony), oraz w zbiorze Waldiks [Leśne], zob. tenże, Waldiks, Wilno 1940 (cytowany fragment utworu oznaczam literą W i podaję numer strony).

${ }^{8}$ Zob. H. Valencia, The Early Poems: 1934-1937 [w:] tejże, „Bashtendikayt” and „Banayung": Theme and Imagery in the Earlier Poetry of Abraham Sutzkever, Stirling 1991, s. 35-36. 
zwłaszcza przewijająca się w wielu wczesnych utworach (na przykład Nacht un der Wanderer [Noc i wędrowiec] czy Af majn wanderfajfl [Na mojej fujarce]) postać podmiotu-wędrowca, który przyjmując względem krajobrazu receptywną postawę, rejestruje zachodzące w nim zjawiska, gromadzi obrazy i wrażenia, jakich w nim doznaje. Wędrowiec w poezji Suckewera jest również tym, który nieustannie poszukuje, jego praktyka rozpoznawania krajobrazu poprzez wędrówkę ma prowadzić do odnalezienia siebie w świecie. W wierszu Litwisze pojerim [Litewscy chłopi] Suckewer konfrontuje dwie aktywności związane z krajobrazem - mieszkańca-chłopa oraz podmiotu-wędrowca, pełniącego również funkcję alter ego poety:

Un ze: fule felder mit korn,

Un lonkes mit waremen hej,

Es wigt zich a blejche topolie.

A pikholc pikt ojset a sztral.

Di pojerim zeen: Di dolie

Ligt blendik un szarf - a kinżal.

Fun klorkajt gelojterte zingen

Zej uf a bahaltenem lid;

Un szlajfn di serpisze klingen

Grejte cum cajtikn sznit... (L, s. 56) ${ }^{9}$.

Z perspektywy chłopów krajobraz utożsamia się z ich „dolą”, życiem, które pozostaje w ścisłym związku z krajobrazem jako przestrzenią zamieszkiwania i codziennej pracy, mającej zapewnić im przetrwanie. Chłopskie podejście do krajobrazu, nakierowane na osiągnięcie konkretnych zysków, ma zatem wymiar użytkowy (jak pisał Theodor Adorno, ,zawody rolnicze, dla których przejawiająca się przyroda jest bezpośrednim obiektem działań, dają, jak wiadomo, mało poczucia krajobrazu" ${ }^{10}$ ). Podmiot widzi natomiast efekt pracy chłopów: „pełne pola zboża”, „łąki z ciepłym sianem”, oraz rejestruje krajobrazowy ruch: „kołysze się blada topola”, „dzięcioł wystukuje promień”. Z jego perspektywy krajobraz składa się z twórczych aktywności, działań mających wymiar kreacyjny, które razem kształtują otoczenie.

Różnice w postrzeganiu krajobrazu wynikają z odmiennych stanowisk reprezentowanych przez chłopów i podmiot. Chłopi zostają pokazani jako określona

9 „I widzę: pola pełne zbóż,/ I łąki z ciepłym sianem,// Kołysze się blada topola./ Dzięcioł wystukuje promień./ Chłopi widzą: nasza dola/ leży oślepiająco i ostro - sztylet.// Z jasności czystej wyśpiewują/ ukrytą pieśń; /I ostrzą sierpowe dźwięki/ gotowe do dojrzałego cięcia...” [tłum. filologiczne - K.K.].

${ }_{10}$ T. Adorno, Teoria estetyczna, tłum. K. Krzemieniowa, Warszawa 1994, s. 120. 
wspólnota, związana z litewskim krajobrazem, która funkcjonuje w jego obrębie. Podmiot natomiast poznaje krajobraz z perspektywy zewnętrznej, kogoś, kto nie należy do wspólnoty i nie ma również dostępu do opisywanego krajobrazu, lub kto świadomie się od niego dystansuje. Dysonans tych perspektyw podkreśla także generalizujące przedstawienie chłopów jako zbiorowości, sygnalizowane już w tytule wiersza Litewscy chtopi, które uwydatnia indywidualizm podmiotu, jego samotność i brak przynależności do wspólnoty. W jego wypadku krajobraz nie konstytuuje się przez akt zamieszkiwania rozumiany jako proces tworzenia okolicy, co ujawnia w ostatniej strofie wzmianka o „ukrytej pieśni” chłopów, która towarzyszy ostrzeniu sierpów. Ich pieśń, symbolizująca tu twórczą siłę i pracę chłopów w krajobrazie, wyznacza granicę poznawczą, której podmiot nie może przekroczyć. Podmiot-wędrowiec wydaje się poszukiwać własnej pieśni, indywidualnej formy uczestniczenia w krajobrazie za pomocą poezji, sposobu pojednania z przyroda, ale nie przez jej opanowywanie czy konkretną pracę. Warto zwrócić uwagę, że na aktywność chłopów w krajobrazie wskazują w wierszu następujące narzędzia pracy na roli: kosy, do których zostają porównane polne ścieżki jako ludzki wytwór, kindżał (sztylet) i sierp. Te ostre przedmioty, które służą chłopskiej pracy, implikują jej przemocowy i destrukcyjny charakter. $\mathrm{Na}$ podobne znaczenie rolniczych narzędzi wskazuje również inny utwór Erdisze himlen [Ziemskie niebiosa] z tomu Waldiks [Leśne], w którym czytamy: „A junge dorfsfroj drimlt/ mitn serp derlebn./ Der serp kukt szarf un cejnik/ cu dem zangenfeld” [„Młoda wiejska kobieta drzemie/ z sierpem u boku/ Sierp szczerzy się surowo/ do łanów zboża” (W, s. 8; tłum. fragm. - K.K.)]. Z perspektywy wędrowca patrzącego na krajobraz w sposób estetyczny ścięcie dojrzałego plonu, które suponuje wielokropek kończący utwór, może wskazywać na niszczenie, redukcję i zachwianie krajobrazowej harmonii.

$\mathrm{Na}$ czym dokładnie miałoby polegać doświadczenie krajobrazu jako przeżycia estetycznego? Próbując odpowiedzieć na to pytanie, warto przywołać zamieszczony w zbiorze Lider cykl utworów zatytułowany Sztern in sznej (sibirer poeme) $[\text { Gwiazdy w śniegu (syberyjski poemat) }]^{11}$. Stanowi on zapis poznawania

${ }^{11}$ Cykl wierszy Sztern in sznej (sibirer poeme) został napisany w 1935 roku, a opublikowany dwa lata później w debiutanckim tomie poetyckim. Stał się podstawą poematu Sibir, nad którym Suckewer pracował już po wojnie i który ostatecznie został opublikowany w 1952 roku w Tel Awiwie (wydanie to ilustrował Marc Chagall). Większość badaczy twórczości Suckewera nie traktowała tych utworów jako odrębnych kompozycji poetyckich, co więcej, późniejszy poemat zdawał się przysłaniać pierwszą realizację. Lektura porównawcza dwóch cykli zaproponowana przez Heather Valencię przekonuje jednak, że dwie wersje „syberyjskiego poematu” znacząco się od siebie różnią - zarówno pod względem problematyki, jak i formy stylistycznej. W porównaniu z cyklem Sztern in sznej forma późniejszego poematu jest bardziej dopracowana, a przedstawione w nim wspomnienia zyskują metaforyczne znaczenia. Istotnego przesunięcia Suckewer dokonuje też w kwestii tematyki - pierwszy cykl koncentruje się przede wszystkim na ukazaniu „nostalgicznej pamięci dzieciństwa”, a drugi na poetyckim przebudzeniu, procesie kształtowania się świadomości poetyckiej. Zob. H. Valencia, Two Longer Poems: „Shtern in shney” and „Sibir” [w:] tejże, „Bashtendikayt” and „Banayung”..., dz. cyt., s. 128-175. 
natury z perspektywy dziecięcego podmiotu (wszak poemat nawiązuje do okresu dzieciństwa spędzonego przez Suckewera na Syberii). Poetycki krajobraz Syberii, jaki tworzy w cyklu Suckewer, łatwo można sobie wyobrazić jako impresjonistyczny obraz wypełniony drobnymi plamami farb, które - gdy patrzy się na nie z oddalenia - tworzą plastyczną całość, z poszczególnych punkcików farb zaczynają wyłaniać się konkretne kształty. Krytycy tak też najczęściej opisują poemat Suckewera - jako próbę uchwycenia krajobrazu w ulotnej chwili. Joni Fajn mówi nawet o „malarskim oku” Suckewera, za pomocą którego poszczególne uczucia, impulsy i idee łączy w konkretne kompozycje obrazowe ${ }^{12}$. W krytycznych omówieniach poematu podkreśla się ponadto - zresztą nie bez przyczyny - że doświadczenie Syberii, a zwłaszcza jej krajobrazu, zaważyło na charakterystycznym dla poety sposobie obrazowania, który ujawnia wrażliwość na zmysłowość natury lub, jak to określa Daniel Kac, „panteizm analityczny”, polegający na ujmowaniu świata w postaci pojedynczych, impresjonistycznych obrazów zjawisk przyrodniczych ${ }^{13}$. Panteistyczna wizja świata, która wyłania się z poezji Suckewera, czerpie inspirację również z filozofii Barucha Spinozy, a zwłaszcza z koncepcji tożsamości natury i Boga (o czym świadczy choćby wiersz $A$ nacht mit Szpinozen [Noc ze Spinoza]).

W wierszu Sibirer friling [Syberyjska wiosna] znajdujemy następujący ciąg asocjacyjnych skojarzeń ukazujących krajobrazową intensywność:
Szojmiker un drejster wert der gegnt.
Di stichie flejct mit farb un klang.
Wi cefochte bajczn faln regns...
Un dos jingl, wos batracht es lang,
Wil ict af di ale tojznt sztromen
Gebn zich a szlejder un a trog
Iber stepes, bejmer, tajchn, thomen,
Cu dem najem frilingdikn tog! - (L, s. 90) $)^{14}$.

To, co najbardziej interesujące w przedstawieniu Syberii, a co nie mieści się już w kategorii impresjonistycznego obrazowania, to próba uchwycenia krajobrazu w ruchu. Synestezyjny tryb opisywania krajobrazu, który koncentruje się przede wszystkim na zarejestrowaniu wrażeń zmysłowych: dźwięków, kolorów czy zapachów, pozwala ukazać drobne poruszenia krajobrazu, jego rozedrganie i pulsowanie. „Syberia w poezji Sutzkevera - pisze Daniel Kac - jest

12 Zob. J. Fajn, Dos molerisze ojg, „Di Goldene Kejt” 1993, nr 136, s. 121.

13 Zob. D. Kac, Wilno Jerozolima byto. Rzecz o Abrahamie Sutzkeverze, Sejny 2003, s. 27-28.

14 „Pienista i zuchwała staje się okolica/ żywioł napływa z kolorem i dźwiękiem./ Jak smagające baty pada deszcz.../ A chłopiec, który obserwuje to długo,/ chce teraz na te tysiące strumieni/ się rzucić i nieśćl przez stepy, drzewa, rzeki, przepaści/ do nowego, wiosennego dnia!" [tłum. filologiczne - K.K.]. 
w ciągłym ruchu. Przestrzeń istnieje w czasie i nie zanika, tak jak nie zanika czas" ${ }^{15}$. Ulotność i zmienność, którą podpowiada kontekst impresjonizmu, nie musi więc odnosić się do samego przedstawienia krajobrazu, lecz może określać sposób jego postrzegania przez podmiot. Opiera się on na braku stabilności, celowej fragmentaryczności, chwilowości i niechęci do kontemplacyjnego oglądu świata. Taki sposób przeżycia estetycznego Adorno nazwał „doświadczeniem bezpośrednim" - spontanicznym i żywiołowym rejestrowaniem zjawiskowości rzeczy, opierającym się bardziej na zaangażowaniu zmysłowym niż na refleksji. W Teorii estetycznej Adorno podkreśla, że doświadczenie piękna naturalnego „odnosi się do przyrody jako zjawiska, a nie jako tworzywa dla pracy i reprodukcji życia, że nie wspomnimy o niej jako substracie wiedzy. Doświadczenie estetyczne przyrody, podobnie jak doświadczenie sztuki, jest doświadczeniem obrazów" ${ }^{16}$. Kategorię zaproponowaną przez Adorno przekonująco tłumaczy Beata Frydryczak, pisząc, że:

Doświadczenie piękna przyrody to jedno z najwcześniejszych doświadczeń jednostki: otwiera się człowiekowi w dzieciństwie i staje się źródłem jego wrażliwości estetycznej cały czas, przez obcowanie z nią, podtrzymywanej. To piękno objawia się w bezwiednym postrzeganiu, w sposób spontaniczny i nierefleksyjny. To rodzaj impulsu o bogatym „energetycznym” podłożu, w którym wyraża się spontaniczność, tęsknota, pragnienie, szczęście, emfatyczna prawda ${ }^{17}$.

W bezpośrednim doświadczaniu piękna syberyjskiego krajobrazu podmiot w poemacie Suckewera jest niezwykle aktywny - swoje działania określa za pomocą takich czasowników, jak biec, skoczyć, lecieć, pędzić czy jechać, które dodatkowo występują w formie gramatycznej momentaler aspekt, wskazującej na krótki czas trwania danej czynności, momentalność, szybkość i intensywność. Poruszenie krajobrazowych elementów wynika zatem z postawy zarówno poznającego, jak i działającego w okolicy dziecięcego podmiotu. Można odnieść wrażenie, że poetycki cykl ukazuje nie tyle proces oswajania obcej i nowej krainy, lecz samo bycie podmiotu w krajobrazie, z którym łączy go pewna bliskość. Dziecięca ciekawość prowadzi do cielesnego i zmysłowego doświadczania okolicy przez gromadzenie własnych odczuć i wrażeń, przez empiryczne sprawdzanie ojcowskich opowieści. Podmiot w syberyjskim krajobrazie odnajduje to, co przyciąga go nie tylko jako małe dziecko - wolność poznawania i możliwość odkrywania tajemnic.

15 D. Kac, dz. cyt., s. 253.

16 T. Adorno, dz. cyt., s. 121.

${ }_{17}$ B. Frydryczak, Krajobraz. Od estetyki "the picturesque” do doświadczenia topograficznego, Poznań 2013, s. 71. 


\section{Przeświecanie materii}

To właśnie możliwość poszukiwania tajemnicy i zarazem obietnica jej odkrycia wydaje się tak przyciągać podmiot wierszy Suckewera do krajobrazu. Rejestrowanie zjawiskowości krajobrazowej materii jest wyrazem podejmowanych przez podmiot prób odnalezienia w przyrodzie metafizycznego sensu przez epifaniczne doświadczenie. Epifanię rozumiem tu - za propozycją Ryszarda Nycza - nie tylko jako teologiczno-religijną kategorię opisującą momenty ingerencji osobowego Boga w rzeczywistość, ale także jako kategorię specyficzną dla literatury nowoczesnej oraz poetyki nowoczesnego dzieła literackiego. Jak wyjaśnia Nycz:

epifaniczna poetyka jest literacką realizacją (czy wersja) formacyjnej cechy struktury myśli nowoczesnej, uznającej, że treść doświadczenia nie daje się odróżnić od warunków jej przejawiania się w owym doświadczeniu. W sferze poetyki nowoczesnej literatury odpowiadałaby temu współzależność cech antynomicznych: w koncepcji dzieła - autonomii i partycypacji czy przynależności; w koncepcji podmiotu - suwerenności i podporządkowania czy ubezwłasnowolnienia; w koncepcji rzeczywistości - poznawczej „niedosięgalności” czy niewyrażalności i znakowego zmediatyzowania ${ }^{18}$.

Nycz wyróżnia trzy rodzaje epifanii: romantyczne, modernistyczne i negatywne. Romantyczny dyskurs epifaniczny, jakiemu patronowała zasada „wyrażania niewyrażalnego", opierał się na przekonaniu o istnieniu esencji rzeczywistości, dla której ukazania poszukiwano adekwatnej formy. Formuła „wyrażania niewyrażalnego" polega w nowoczesnych epifaniach na nadawaniu formy i znaczenia czemuś, co pozostaje nieokreślone i bezkształtne. Nowoczesne epifanie są zapisami intensywnych, momentalnych i przygodnych śladów obecności rzeczy powszednich:

objawieniami - raczej świeckimi niż boskimi - tego, co nie bezpośrednio widoczne (a nie tego, co samo wprost się ukazuje), poszczególne (nie tego, co ogólne i uniwersalne), przygodne (nie tego, co esencjalne czy konieczne), momentalne (nie tego, co wieczne i niezmienne) oraz ucieleśnione, realnie istniejące (a nie tego, co idealne i czysto duchowe) ${ }^{19}$.

Epifaniami negatywnymi, charakterystycznymi dla twórczości ponowoczesnej, Nycz nazywa z kolei dokumentacje przygodności i nieuchwytności bycia, tego, co wymyka się obrazowemu, językowemu czy pojęciowemu

${ }_{18}$ R. Nycz, Literatura jako trop rzeczywistości. Poetyka epifanii w nowoczesnej literaturze polskiej, Kraków 2012, s. 10.

19 Tamże, s. 47-49, 89. 
przedstawieniu. W poezji Suckewera splatają się dwojakie realizacje doświadczenia epifanii: romantycznej, która opisuje dążenie do odkrycia istoty i sensu rzeczywistości, i nowoczesnej, próbującej uchwycić, to co nieuchwytne.

Epifanijne doświadczanie krajobrazu, zapisane w utworach Suckwera, będzie się opierało na wydobywaniu z rzeczy światła transcendencji i uchwyceniu w nich blasku metafizyki. Wczesna poezja Suckewera operuje rozbudowaną metaforyka, za pomocą której autor stara się uchwycić przebłysk esencji. Źródłem epifanijnego światła w poezji Suckewera są elementy krajobrazowe: srebrzysty stóg siana (A skirde hej [Stóg siana], L, s. 60), błyszczące krople rosy, światło, święto świtu (Blonder baginen [Jasny świt], L, s. 36), promienie i słoneczne wizje (Baszafung [Stworzenie], L, s. 28), srebrzysto-zielona rzeka (Di randn fun a tajch [Brzegi rzeki], W, s. 10); narzędzia: ostrze pługu (Erd un aker [Ziemia i pług], L, s. 30), sztylet, kosa i sierp (Litwisze pojerim [Litewscy chłopi]), niebieski nóż (Majn ojsgebenkter szejwet); kolory: niebieski (Hejmisze felder [Swojskie pola]), biała kora brzóz (Blonder baginen, Hejmisze felder), biała, drewniana łyżka (Dos gezang wegn hilcernem lefl [Pieśń o drewnianej łyżce], L, s. 62), przejrzysty lazur (Durch zunike necht [Przez słoneczne noce], W, s. 6). W duchu romantycznych epifanii Suckewer dąży do prześwietlania rzeczy i wydobywania z nich „światła noumenalnego”, istotowego blasku. Icchok Janasowicz nazywa Suckewera „permanentnym odkrywcą”, który przez zaszyfrowany znak opisuje ludzkie poznawanie tajemnicy świata ${ }^{20}$.

W przywołanym cyklu poetyckim Sztern in sznej krajobraz Syberii jest również rozświetlony - podmiot odkrywa w nim różne rodzaje światła: $\mathrm{z}$ jednej strony jego źródła, jak słońce, gwiazdy czy chatka, w której mieszka dziecko, z drugiej przedmioty, które światło odbijają, na przykład księżyc, śnieg (w wierszu Sznej określony za pomocą epitetów „błękitny”, „diamentowy”) ${ }^{21}$ czy siekiera ojca. Wydaje się zatem, że identyfikowanie źródeł światła zmierza do wydobycia z krajobrazu tego największego - duchowego, metafizycznego, panteistycznego. Podobnie jak śnieg odbija światło, świat ziemski zawiera w sobie blask wieczności, czegoś, co wykracza poza granice materialnego świata.

Przeświecanie wiecznego w przemijającym umożliwia postrzeżeniowe i wrażeniowe percypowanie krajobrazu. Wrażenie opiera się reprezentacji, podmiot może je uchwycić przez asocjacyjne połączenia obrazów, które mają ukazać rzeczywistość w nowej odsłonie. Epifania staje się więc formą przeżycia estetycznego, którego podmiot doświadcza nie tyle przez kontemplację, ile aktywne uczestniczenie w krajobrazie i identyfikowanie wrażeń. Prześwietlanie rzeczy zmierzałoby również do uchwycenia piękna krajobrazu, piękna naturalnego

${ }_{20}$ Zob. I. Janasowicz, Awrom Suckewer. Zajn lid un zajn proze, Tel Awiw 1981, s. 17.

${ }^{21}$ David Roskies zauważa, że śnieg jest głównym elementem poetyckiego krajobrazu Suckewera, będącym symbolem „czystości, miłosierdzia i odrodzenia”, a w pisanej podczas Zagłady poezji został skojarzony ze śmiercią syna. Zob. tenże, Against the Apocalypse: Responses to Catastrophe in Modern Jewish Culture, Syracuse 1999, s. 236-237. 
jako „zaskakującej obietnicy czegoś najwyższego”. Pisząc o pięknie natury, Adorno podkreślał, że:

Jeżeli już gdzieś szukać czynnika jakościowo wyróżniającego piękno przyrody, to tylko w tym, jak bardzo przemawia coś, co nie jest zrobione przez człowieka, w jej ekspresji. Piękne w przyrodzie jest to, co jawi się jako coś więcej niż ona sama w sobie w konkretnym miejscu i czasie ${ }^{22}$.

\section{Epifanie niespełnione?}

Epifanie nowoczesne są wobec transcendencji podejrzliwe i nieufne - nie ma w nich romantycznego zadomowienia w sensie, a więc przekonania, że nie tylko możliwe jest dosięgnięcie esencji, ale przede wszystkim - że esencja ta istnieje. „Modernistyczne epifanie zrodziłyby - zapewne jak większa część nowoczesnej sztuki - lęk przed tym co Inne"23. Poezja Suckewera ukazuje proces paradoksalnych poszukiwań, w których podskórne przeczucie istnienia sensu rzeczywistości, oczekiwanie na jego objawienie łączy się z podejrzeniem, że wyglądy rzeczy nie kryją żadnej duchowej istoty. W wierszu Blonder baginen [Jasny świt] poeta buduje atmosferę oczekiwania na „święto jasnego świtu”:

Der tol wert ufgehilcht.

Siz hojler klang.

Der morgnsztern wacht.

Di farbn rinen.

Ich wasz arop in sażlke

Fun zich di bloje nacht,

Un grejt zich cu dem jon-tew

Fun baginen (L, s. 37) ${ }^{24}$.

Metaforyczne nazwanie świtu świętem wskazuje zarówno na doniosłość i znaczenie tego wydarzenia jako początku dnia (i zarazem kreacyjnego początku), jak i również na oczekiwanie na doświadczenie duchowego wymiaru rzeczywistości. Akt zmycia z siebie niebieskiej nocy ma przygotować podmiot

22 T. Adorno, dz. cyt., s. 131.

${ }^{23}$ R. Nycz, dz. cyt., s. 48.

${ }^{24}$ „W dolinie nuta żywa/ czystym dźwiękiem się niesie,/ gwiazda poranna czuwa/ i barwą nocy spływa.// Błoto nocy zmywam/ w stawie na sobie/ i do święta jutrzenki/ się sposobię" [tłum. - Zew Szeps]. Zob. A. Suckewer, Jasny świt (fragment) [w:] D. Kac, dz. cyt., s. 288. 
na przė̇ywanie czegoś, co stanie się nie tylko medium transcendencji czy medium samej poezji, ale także duchowym fenomenem jako takim, przejawem formy jednostkowej rzeczy. W takim ujęciu epifanijnego doświadczania krajobrazu Suckewer zbliża się do rozumienia epifanii jako nostalgicznego dążenia do tego, co nieosiągalne, jako oczekiwania - zgodnie z formułą Czesława Miłosza - „na chwilę poznania, na nagły błysk objawienia, który odkryje sens, zagubiony bezpowrotnie sens świata i naszego życia na ziemi" ${ }^{25}$. Poszukiwania sensu w poezji Suckewera motywuje nostalgia za tym, co niedościgłe, za pięknem, które „postrzegane jako nostalgiczne jest aluzją do czegoś, co samo nie pozwala się w pełni uobecnić" ${ }^{26}$. Marek Zaleski pisze o tym tak:

Ja nostalgiczne to także ja bez siebie, ja w separacji z samym sobą, wydrążone i skazane na nieustanne studiowanie stanu pustki i bólu rozłączenia. Jednak nieodmiennie jest to ja, a nie miejsce, które dopiero jako obszar na mapie doświadczenia zostaje zabarwione udręką ja w poszukiwaniu samego siebie ${ }^{27}$.

W swojej twórczości Suckewer rejestruje przede wszystkim sam proces dążenia do transcendentnego - podejmowania wysiłku odkrywania, poszukiwania czy wędrowania w krajobrazie. Rezultat takich dążeń okazuje się niedostępny dla podmiotu, na końcu jego drogi nie ma objawienia istoty rzeczywistości. Taką „niespełnioną epifanię" ukazuje wiersz Ot bin ich doch... [Oto jestem przecież...], w którym czytamy:

Ot bin ich doch, an ufgebliter in majn gancer grejt.

Farsztochn mit gezangen wi mit fajerdike binen.

Ich hob derhert dajn ruf cu mir fun lichtikn baginen

Un zich cu dir awekgelozt durch nacht un sztojb un szwejs.

Es hobn sztet un derfer zich fun mir awekgerisn.

(...)

Ich c'bin geblibn far dajn nomen sztejn.

Wi farn blojen szpigl fun gewisn.

Di hent majne - wi cwajgn opgeszundene

Klapn hastik in dajn heler tir.

Di ojgn majne - capldik-farwunderte

Cijen zich wi zeglen cwej cu dir.

Nor mitamol: - di tir iz ofn.

Bist niszto.

Siz alc antlofn.

${ }^{25}$ C. Miłosz, O milczeniu, „Ateneum” 1938, nr 2, s. 138-143.

${ }^{26}$ M. Zaleski, Formy pamięci. O przedstawianiu przesztości w polskiej literaturze wspótczesnej, Warszawa 1996, s. 16.

27 Tamże. 
Bist niszto.

Es blajbt a lid.

A nariszer gewejn.

A niszt-farsztejn (L, s. 19) ${ }^{28}$.

Przywołany utwór jest zapisem poetyckiego dążenia do odkrycia dos wortSłowa, które będzie transparentne wobec rzeczywistości, w adekwatny sposób pozwoli uchwycić materię (w kontekście metapoetyckim) lub doświadczyć piękna i dotrzeć do poznania sensu świata, co ma się spełnić w akcie epifanii (w kontekście egzystencjalno-epistemologicznym). Centralnym motywem, organizującym kompozycję wypowiedzi lirycznej, jest wezwanie, wołanie ( $r u f$ ), które podmiot dosłyszał. Użycie czasownika derhern (dosłyszeć), sugerujące szczególny wysiłek i usilne staranie podmiotu, odnosi się zarazem do specyfiki tego dźwięku - nie jest on konkretny, lecz chwilowy, efemeryczny i słaby. Źródło, z jakiego pochodzi, również nie jest precyzyjnie określone, wiadomo tylko, że należy on do adresata wypowiedzi, do którego podmiot zwraca się bezpośrednio.

Podążając tropem symboli metapoetyckich, zawartych w wierszu (takich jak pszczoła czy śpiew), można przyjąć, że wołanie jest źródłem poezji, wskazuje na inspirację, twórczą siłę lub poetycką wizję, które determinują proces tworzenia polegający na przekształcaniu niejasnych, mglistych i niemających konkretnego znaczenia dźwięków w poetycką formę. Awrom Nowersztern, omawiając znaczenie pszczoły jako metapoetyckiego symbolu w poezji Suckewera, stwierdza, że „podobnie jak pszczoła poeta również dokonuje metamorfozy, w ramach której materiał, jaki w siebie wchłania, otrzymuje w ostatecznym rozrachunku zupełnie inną jakość" ${ }^{29}$. Metapoetyckie rozważania na temat procesu twórczego zdają się jednak jednym z problemów, jakie w swoim wierszu porusza Suckewer. Dźwięk może bowiem przywoływać myśl o tajemnicy, która jest ukryta za drzwiami i przyciąga poetę. W tym kontekście wołanie wiązałoby się z (wewnętrznym) pragnieniem poznania tajemnic świata oraz życia, a sam akt twórczy stawałby się formą poznawania świata, odkrywania metafizycznego sensu.

Prawdą, którą podmiot odkrywa na swojej poetyckiej drodze zapisanej w kolejnych wersach, jest fundamentalna niewystarczalność języka jako narzędzia do opisu świata i uchwycenia piękna, a z drugiej strony niemożność poznania.

28 „Oto jestem przecież, kwitnący w mojej pełni./ Ukąszony śpiewem jak przez płonące pszczoły./ Dosłyszałem twoje wołanie do mnie z jasnego świtu/ i udałem się do ciebie przez noc, kurz i pot./ Miasta i wsie oderwały się ode mnie. (...) Stałem przed twoim imieniem./ Jak przed niebieskim lustrem wiedzy./ Moje ręce - jak obdarte z kory gałęzie/ uderzają gwałtownie w twoje jasne drzwi./ Moje oczy - na nowo zadziwione/ ciągną się do ciebie jak dwa żagle./ I nagle - drzwi są otwarte./ Nie ma cię./ Wszystko uciekło./ Nie ma cię./ Pozostał wiersz./ Głupi płacz./ Niezrozumienie [tłum. filologiczne - K.K.].

29 A. Nowersztern, dz. cyt., s. 190. 
Okazuje się bowiem, że za drzwiami „nie ma nic” i „wszystko się ulotniło”. Nawet poeta przekonany o swoich twórczych zdolnościach i mający już pewne doświadczenie, który czuje się przygotowany do konfrontacji z prawdą (co wyraża przede wszystkim tytułowa formuła „ot bin ich doch...”), jak sam siebie opisuje podmiot wiersza, nie potrafi uchwycić sensu. Poprzez akt poetyckiego tworzenia może on jedynie przybliżać się do źródła tajemnicy. Podobny motyw dążenia do odkrycia tajemnicy ukazuje Bolesław Leśmian w balladzie Dziewczyna (będącej skądinąd jednym z ulubionych utworów Leśmianowskich Suckewe$\mathrm{ra}^{30}$ ), w której dwunastu braci próbuje zniszczyć mur, aby uwolnić znajdującą się za nim dziewczynę. Na jej istnienie wskazuje jedynie głos odsyłający podobnie jak w wierszu Suckewera - do tajemnicy istnienia i metafizycznej siły niosącej w sobie obietnicę świata duchowego.

Odkryta na końcu poetyckiej drogi prawda przynosi rozczarowanie, bezsilność i pesymizm, które pozbawiają poetę wiary w swoje możliwości twórcze i poznawcze, odmawiają mu tego statusu, jaki sam sobie przyznał na początku wiersza. Zrzucenie podmiotu z wyżyn poetyckiego uniesienia i dumy odzwierciedla sama kompozycja utworu, polegająca na pomniejszaniu kolejnych wersów, używaniu coraz mniejszej liczby słów i swego rodzaju „zwijaniu” znaczeń. Ta struktura wiersza wyraża również pośrednio afektywny wymiar podmiotowego doświadczenia, jego cielesną reakcję na rozczarowanie - obrazuje bowiem zaciskanie się gardła, powstrzymywanie płaczu, co w konsekwencji uniemożliwia mówienie. Forma poetycka zatem pozwala na opanowywanie siły afektu, sublimację gwałtownych doznań i intensywnych przeżyćc ${ }^{31}$, a także pełni funkcję „estetycznego pancerza”, który utrzymuje w ryzach chaotyczny żywioł dionizyjskości ${ }^{32}$. Zobrazowany $\mathrm{w}$ formie wiersza problem niewyrażalności może odnosić się również do próby uchwycenia naturalnego piękna, z góry skazanej na porażkę. Adorno podkreślał, że każda cząstka przyrody prześwieca od wewnątrz, z czego wynika nieokreśloność piękna. „Jak w muzyce to, co jest piękne, rozbłyska w przyrodzie, aby natychmiast zniknąć w obliczu próby pochwycenia go" ${ }^{33}$. Dlatego też najwłaściwszą reakcją na piękno natury, zdaniem Adorno, byłoby milczenie, gdyż każda próba jego przedstawienia (słownego czy obrazowego) może stać się formą uprzedmiotowienia i pomniejszenia. Poezja Suckewera pokazuje, że uchwycenie piękna w krajobrazie nie jest możliwe

30 Taką informację przekazywał w swoich wspomnieniach o Suckewerze Natan Gross, który opowiadał, że Suckewer - nawet po wielu latach od emigracji do Izraela - swobodnie recytował utwory Leśmiana. Zob. D. Kac, dz. cyt., s. 94.

${ }^{31}$ Nowersztern mówi o technice sublimacji jako budowania dystansu między doświadczeniem podmiotu a aktem tworzenia. Zob. A. Nowersztern, dz. cyt., s. 196.

32 Zob. Ch. Rosenfarb, Dos gan-ejdn-jingl Awrom Suckewer, „Di Goldene Kejt” 1993, nr 136, s. 25. Autorka proponuje bardzo inspirującą lekturę twórczości Suckewera. Posługuje się proponowanym przez Nietzschego rozróżnieniem na apollińskość i dionizyjskość, twierdząc, że w twórczości Suckewera są one ze sobą ściśle sprzężone.

33 T. Adorno, dz. cyt., s. 134. 
ze względu na paradoks języka, określający niewspółmierność słowa i myśli, zjawiska i istoty oraz nieadekwatność wyrazu wobec rzeczy ${ }^{34}$.

Niespełniona epifania pozostawia jednak ślad, którym jest wiersz nazwany „głupim płaczem” i ,niezrozumieniem”, będący resztką podmiotowego doświadczenia. Wydaje się zatem, że akt twórczy paradoksalnie odnajduje swoje źródło w rozczarowaniu pustką bytu, doznanie to staje się - niemal masochistycznie - czymś, co poetę przyciąga, co determinuje jego kolejne poszukiwania i próby doświadczenia epifanii. W szkicu Dos gan-ejdn-jingl Awrom Suckewer Chava Rosenfarb stwierdza, że w przypadku Suckewera pisanie nie tylko legitymizuje egzystencję, ale samo jest jego egzystencją. Radość pisania przynosi nieodłącznie ból rodzenia i tworzenia. Jak pisze Rosenfarb, twórczość Suckewera wywołuje wrażenie, że autor darzy pisanie „chorobliwą i perwersyjną miłością" ${ }^{35}$. Na dwuznaczność poetyckiego aktu twórczego wskazuje również symbol pszczoły - tworzenie z jednej strony stanowi ciężką pracę, wymaga wysiłku, dyscypliny i cierpliwości, z drugiej natomiast jest, niczym ukąszenie pszczoły, nagłym, ale i bolesnym doznaniem piękna ${ }^{36}$.

Takie rozumienie epifanijnych doświadczeń krajobrazu wiąże się nieuchronnie z ograniczaniem i redukowaniem „ja” - rozczarowanie jest tym doznaniem, które nadkrusza ludzką podmiotowość. Akt twórczy, w wyniku którego kształtują się nowe dzieła lub zjawiska przyjmują inne postaci, wymaga porzucenia swojej dotychczasowej formy, przekroczenia niejako granic własnej podmiotowości i indywidualności (w wierszu Ot bin ich doch... wskazuje na to metamorfoza podmiotu w drzewo, którego gałęzie zostają odarte z kory). Wydaje się jednak, że proces ten nie musi być rozumiany negatywnie - poezja, wiążąca się z pełnym zaangażowaniem i wysiłkiem, może stać się przestrzenią potencjalności podmiotu, jego procesu stawania się, podczas którego zawiązują się relacje ze światem i odkrywana jest fundamentalna łączność z przyrodą. Bezpośrednie doświadczenie krajobrazu pozwala zatem podmiotowi odkryć też własną przyrodniczość. Decyduje to o płynnym statusie ontologicznym podmiotu

${ }^{34}$ Karolina Szymaniak formułuje hipotezę o dwóch drogach modernizmu jidysz w Polsce, którym mieliby patronować z jednej strony Debora Vogel, a z drugiej Awrom Suckewer. Autorka - odnosząc się do koncepcji tropów „ja” Ryszarda Nycza - określa drogę Debory Vogel jako „drogę metatropu alegorii”, u której podstawy leżą właściwe awangardzie melancholijne doświadczenie utraty kontaktu z ukrytym porządkiem oraz poczucie rozpadu. Droga ironii, którą Szymaniak przypisuje Suckewerowi (dokładniej - jego wczesnej twórczości, której kres i punkt zwrotny wyznacza doświadczenie Zagłady), opiera się na dostrzeżeniu paradoksu języka, jego nieodpowiedniości względem rzeczy. Zob. K. Szymaniak, Być agentem wiecznej idei. Przemiany pogladów estetycznych Debory Vogel, Kraków 2006, s. 217-222. Icchok Janasowicz również podkreśla, że Suckewer „żył wizją modernistycznego człowieka, a swoim słowem i muzyką próbował artystycznie definiować i formułować to, co nowe w ludzkim duchu”; i tak jak czołowi przedstawiciele europejskiego modernizmu próbował uchwycić to, co mieści się pomiędzy wyrażeniem a przedstawieniem (reprezentacja). Zob. I. Janasowicz, dz. cyt., s. 17.

${ }^{35}$ Zob. Ch. Rosenfarb, dz. cyt., s. 24.

${ }^{36}$ Zob. A. Nowersztern, dz. cyt., s. 190. 
Suckewera - jego funkcjonowaniu pomiędzy ludzkim i nie-ludzkim, przyrodniczym i kulturowym. W zakończeniu utworu $A$ skirde hej [Stóg siana] podmiot wyraża pragnienie metamorfozy, która pozwoli odkryć inną postać siebie: „Ich lig in hej - a wanderer a mider/ bizwanen c’wer alejn a skirde hej” [„Leżę w sianie - wędrowiec zmęczony/ dopóki nie stanę się sam stogiem siana” (L, s. 60; tłum. - K.K.)]. W wierszu In opgrunt fun a zang [W szczelinie kłosa] ze zbioru Waldiks podmiot stwierdza natomiast: „Un durch majn guf hot plucem/ geton a fli, a tanc/ majn gajst un zich fartajnegt/ in korener substanc:/ ich hob in ir derotemt” [„I nagle przez moje ciało/ wyleciał, zatańczył/ duch mój i się zachwycił/ korową substancją:/ w niej odetchnąłem" (W, s. 24; tłum. - K.K.)].

\section{Podsumowanie}

Realna obecność rzeczy przejawia się w poezji Suckewera poprzez ulotne, momentalne i trudne do uchwycenia oznaki. Promyki, dźwięki, sygnały, błyski, zapachy - to symptomy indywidualnych istnień, ślady niepowtarzalnej aury rzeczy zwykłych, „cud jasnego dziania się”, jak rejestruje podmiot wiersza Blonder baginen. Fragmentaryczne przejawy rzeczywistości wywołują w nim „nagłe wezwanie", rodzaj powołania do twórczego działania. Sztuka poetycka oznaczałaby nie tylko utrwalenie tego, co przypadkowe, szczątkowe w poetyckiej formie, ale stanowiłaby również proces poszukiwania metafizycznych zdziwień, odkrywania i rozszyfrowywania śladów egzystencjalnego sensu w przyrodzie przez praktykę artystyczną. Podobnie jak w leśmianowskiej poetyce, język poetycki staje się narzędziem poznawczym, sposobem docierania do niedostępnych na co dzień form rzeczywistości.

Wczesna twórczość Suckewera nie tylko więc wpisuje się w główny nurt modernistycznych poszukiwań tego, co wieczne i istotowe, ale także wskazuje na fundamentalny brak towarzyszący ludzkiemu istnieniu, jest zapisem doświadczenia nostalgii za tym, co nieosiągalne. Wydaje się bowiem, że istotniejszy od samego efektu poznania - tego, co znajdzie się na końcu wędrówki i wysiłku twórczego - jest w poezji Suckewera sam proces sprawdzania granic poznawczych, empirycznego doświadczania rzeczywistości i wychwytywania momentów epifanijnych. Towarzyszy temu doświadczeniu świadomość, że samo dzieło jest - jak określał je Ryszard Nycz - „negatywną epifanią”, czyli śladem niemożliwej do wypowiedzenia, pozostającej poza przedstawieniem rzeczywistości ${ }^{37}$. Podmiot Suckewera sytuuje się wobec krajobrazu mimo wszystko jako wobec bytu odrębnego, jego celem nie jest bowiem opanowanie żywiołu natury za pomocą poetyckiego słowa, ale przybliżenie się do tajemnicy i sensu, bezpośrednie doświadczenie piękna natury. W tym nieustannym zbliżaniu się do

${ }^{37}$ R. Nycz, dz. cyt., s. 49. 
metafizycznego sensu i podejmowaniu prób na nowo zawiera się sens ludzkiej aktywności - nawet jeśli pełne poznanie nie jest możliwe i podmiot za każdym razem będzie ponosił porażkę.

\section{Bibliografia}

Adorno T., Teoria estetyczna, tłum. K. Krzemieniowa, Warszawa 1994.

Birnbojm J., Awrom Suckewer [w:] Der leksikon fun najer jidiszer literatur, t. 6, Nowy Jork 1965.

Cammy J., Abraham Sutzkever (Avrom Sutskever) [w:] Writers in Yiddish, red. J. Sherman, Detroit 2007.

Cammy J.D., "Ceworfene Bleter”: Jung Wilne i kultura jidysz w międzywojennym Wilnie [w:] Poezja i poeci w Wilnie lat 1920-1940. Studia, red. T. Bujnicki, K. Biedrzycki, Kraków 2003.

Fajn J., Dos molerisze ojg, „Di Goldene Kejt” 1993, nr 136.

Frydryczak B., Krajobraz. Od estetyki „the picturesque” do doświadczenia topograficznego, Poznań 2013.

Janasowicz I., Awrom Suckewer. Zajn lid un zajn proze, Tel Awiw 1981.

Kac D., Wilno Jerozolima byto. Rzecz o Abrahamie Sutzkeverze, Sejny 2003.

Lisek J., Jung Wilne - żydowska grupa artystyczna, Wrocław 2005.

Litwin M., Der driter period in Awrom Suckewers poezje [w:] Jiches fun lid. Lekowed Awrom Suckewer, red. D. Sadan, Tel Awiw 1983.

Miłosz C., O milczeniu, „Ateneum” 1938, nr 2.

Nowersztern A., Der narcis un der regn [w:] Jiches fun lid. Lekowed Awrom Suckewer, red. D. Sadan, Tel Awiw 1983.

Nycz R., Literatura jako trop rzeczywistości. Poetyka epifanii $w$ nowoczesnej literaturze polskiej, Kraków 2012.

Rosenfarb Ch., Dos gan-ejdn-jingl Awrom Suckewer, „Di Goldene Kejt” 1993, nr 136.

Roskies D., Against the Apocalypse: Responses to Catastrophe in Modern Jewish Culture, Syracuse 1999.

Shmeruk Ch., Awrom Suckewer i polska poezja. Juliusz Stowacki w poemacie „Cu Pojln”, tłum. M. Adamczyk-Garbowska [w:] Polskie tematy i konteksty literatury żydowskiej, red. E. Prokop-Janiec, M. Tuszewicki, Kraków 2014.

Shmeruk Ch., Awrom Suckewer un pojlisze poezje: Juliusz Slowacki un der poemat „Cu Pojln” [w:] Jiches fun lid. Lekowed Awrom Suckewer, red. D. Sadan, Tel Awiw 1983.

Suckewer A., Lider, Warszawa 1937.

Suckewer A., Waldiks, Wilno 1940.

Szymaniak K., Być agentem wiecznej idei. Przemiany pogladów estetycznych Debory Vogel, Kraków 2006. 
Valencia H.M., "Bashtendikayt” and „Banayung”: Theme and Imagery in the Earlier Poetry of Abraham Sutzkever, Stirling 1991.

Wisse R., Sutzkever, Avrom, YIVO Encyclopedia of Jews in Eastern Europe, 2017, http://www.yivoencyclopedia.org/article.aspx/Sutzkever_Avrom, dostęp: 6.08. 2018.

Zaleski M., Formy pamięci. O przedstawianiu przesztości w polskiej literaturze wspótczesnej, Warszawa 1996. 